\title{
Sistem Pemantauan Ketebalan Debu \& Suhu Pada Ruangan Menggunakan Aplikasi Telegram Berbasis IoT
}

\author{
Fahri Syeha Maulana* ${ }^{1}$, Agum Prima Pratama ${ }^{2}$, Rini Suwartika Kusumadiarti ${ }^{3}$ \\ ${ }^{1,2}$ Politeknik Piksi Ganesha; Jl. Jend Gatot Subroto 301 Bandung 40274, Telp 022-873 400 Fax \\ 022-87340086 \\ ${ }^{3}$ Jurusan Teknik Informatika dan Komputer, IT PPG, Bandung \\ e-mail: *11 piksi.fahri.18304014@ gmail.com, ${ }^{2}$ agumprima261999@gmail.com, \\ 3rinisuwartika@gmail.com
}

\begin{abstract}
Abstrak
Dengan mengikuti kemajuan teknologi yang ada di dunia ini, kebanyakan orang ingin melakukan segala sesuatu dengan mudah, praktis. tanpa mengganggu pekerjaan yang mereka lakukan di masa pandemi saat ini, teknologi juga sangat dibutuhkan oleh perusahaanperusahaan besar dimana banyak pekerjanya berada di rumah (Work From Home), sehingga tempat perusahaan besar tersebut hanyalah sebuah bangunan besar yang kosong dan terbengkalai . Untuk mengantisipasi bangunan terlantar maka perlu dilakukan cross check secara berkala agar bangunan tetap terjaga kebersihannya dan untuk memudahkan kita melakukan cross check, dengan menggunakan teknologi Internet Of Things (IoT). Dengan mengamati dan menganalisisnya, dibuatlah Sistem Pemantauan Debu dan Suhu. dibuat menggunakan Telegram. Tujuan dari perancangan ini sendiri untuk memudahkan memantau ruangan yang kosong dari jarak jauh dengan menggunakan aplikasi yang biasa digunakan sehari-hari, dimana hasil dari alat ini berupa tampilan besaran jumlah ketebalan debu dan suhu yang dikeluarkan pada aplikasi Telegram.
\end{abstract}

Kata kunci- Arduino, sensor GP2Y1010AU0F, sensor DTH11, Telegram

\begin{abstract}
By following the technological advamces in this world, most people want to do everything easily, practically. without interfering with the work they are doing during the current pandemic, technology is also urgently needed by large companies where many of the workers are at home (Work From Home), so the place for the big company is just a big empty and abandoned building. To anticipate abandoned buildings, it is necessary to do cross checks periodically so that the buildings are kept clean and to make it easier for us to do cross checks, using Internet Of Things (IoT) technology. By observing and analyzing it, a Dust and Temperature Monitoring System was created. created using Telegram. The purpose of this design itself is to make it easier to monitor an empty room remotely using an application that is commonly used daily, where the results of this tool are in the form of displaying the amount of dust thickness and temperature released in the Telegram application.
\end{abstract}

Keywords - Arduino, GP2Y1010AU0F sensor, DTH11 sensor, Telegram 


\section{PENDAHULUAN}

Dengan berjalannya waktu teknologi berkembang sangat pesat, terlebih lagi perihal yang tadinya dikira tidak bisa jadi mungkin terjadi akibat adanya teknologi. Karena banyak media yang terlahir dari teknologi dalam berbagai bidang yang memudahkan manusia dalam menjalankan pekerjaan sehari-hari dengan cepat dan efektif. Seperti contohnya banyak alat disediakan yang berbasis IoT(Internet Of Things). Internet of things (IoT) ini sendiri merupakan sebuah konsep yang menghubungkan semua objek ke internet dan memungkinkan mereka untuk berkomunikasi satu sama lain. Internet of Things (IoT) merupakan jaringan besar perangkat yang saling berhubungan yang secara kolektif menyatukan dan bertukar data tentang bagaimana mereka digunakan serta lingkungan mana perangkat akan bekerja.[1]

Karyawan bekerja di kantor setiap hari sebelum wabah atau pandemi, tetapi setelah wabah ini semakin besar populasinya, mereka wajib bekerja dari rumah (Work From Home) sebagaimana ditentukan dalam perintah gubernur atau kepala daerah dalam penerapan PSBB atau PPKM dikawasannya masing-masing. Bekerja dari rumah (WFH) didefinisikan sebagai karyawan yang melakukan kegiatan atau bekerja di kantor dari rumah sesuai dengan instruksi dan tugas yang diberikan.[2] Yang dimana kebersihan sangat penting disituasi pandemic seperti ini. Bila sewaktu-waktu ruangan akan dipakai maka debu-debu yang sudah penuh menyelimuti ruangan bisa dihindari dari jauh waktu sebelumnya dengan selalu memantau ruangan tersebut. Suhu tidak kalah pentingnya untuk dipantau, suhu ruangan juga harus tetap dicek dengan rutin. Bagi ruangan ini merupakan salah satu hal yang bisa terbilang penting untuk selalu memantau tiap waktu. Karena Kenaikan suhu yang cepat juga dapat menunjukkan adanya kebakaran. Kenaikan atau turunnya suhu juga mempengaruhi untuk kesehatan bagi manusia yang sedang disekitaran ruangan tersebut.[3]

Berdasarkan dari penelitian sebelumnya, perangkat yang digunakan untuk display adalah LCD, dan sistem monitoringnya adalah SMS gateway.[4] Berbeda dengan sebelumnya kali ini memonitoring memberikan pesan menggunakan BotChat di Telegram. Telegram Bot adalah program yang beroperasi sebagai pihak ketiga pada sistem Telegram, ini merupakan salah satu dari fasilitas yang tersedia di Telegram. Aplikasi ini dipakai karena multiplatform yang terbilang ringan, tidak berbayar, dengan BOT API terbilang cukup komplet dan berkembang yang membolehkan pengelola jaringan untuk membangun bot secara dinamis serta cerdas.[5] Kita dapat mengontrol bot seperti memberi pesan, perintah, juga permintaan sebaris dapat dikirim oleh pengguna. Bot dapat dikontrol menggunakan API Telegram melalui HTTPS.[6] Serta akan menggabungkan bagaimana cara mengimplementasikan penggunaan dengan sensor debu GP2Y1010AUOF dan sensor suhu DHT11 menggunakan outputan media aplikasi chat Telegram Bot, untuk memantau ruangan secara real time.

\section{METODE PENELITIAN}

Dalam penelitian ini, disini peneliti menggunakan metode kualitatif dengan melakukan penelitian deskriptif. Yang dimana metode kualitatif sendiri merupakan suatu metode di mana peneliti memanfaatkan peneliti sebagai instrumen utama untuk meneliti keadaan alam tanpa berusaha menentukan pengaruh faktor-faktor tertentu terhadap variabel lain. Penelitian kualitatif mempertimbangkan opini subjektif subjek secara objektif. Penelitian kualitatif yang bertujuan mendapatkan pengetahuan dari ungkapan sudut pandang penulis, dan bukan untuk mengevaluasi subjek dan jalannya terhadap kriteria eksternal penulis.[7]

Maulana, et., al [Sistem Pemantauan Ketebalan Debu \& Suhu Pada Ruangan Menggunakan Aplikasi Telegram Berbasis IoT] 


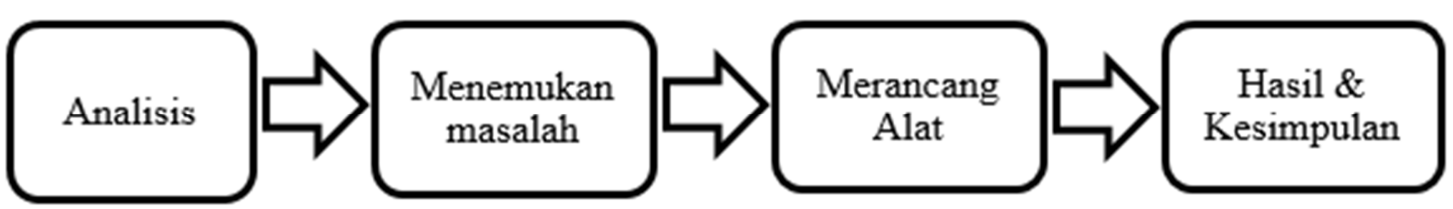

Gambar 1 Alur Metode Penelitian

Penelitian dimulai dengan menganalisis objek penelitian disebuah ruangan perusahaan yang tidak terpakai selanjutnya menentukan sebuah masalah dengan mengamati dan mempelajarinya langsung ditempat. Sehingga perancangan alat bisa sesuai dengan kondisi yang diinginkan, oleh sebab itu perancangan alat disesuaikan dengan situasi dan kondisi saat ini karena kebanyakan ruangan akan kosong diakibatkan banyaknya perusahaan melakukan WFH(Work From Home) dan ruangan kantor pun tidak terpantau, yang seharusnya bisa memberikan opsi dengan adanya alat ini. Kesimpulan yang terpenting dari hasil perancangan alat ini ialah memberikan kemudahan dalam hal memantau atau memonitoring ruangan yang tidak terpakai dari jarak jauh secara real time.

berikut pada gambar 2 adalah skema flowchat berdasarkan alat yang dirancang :

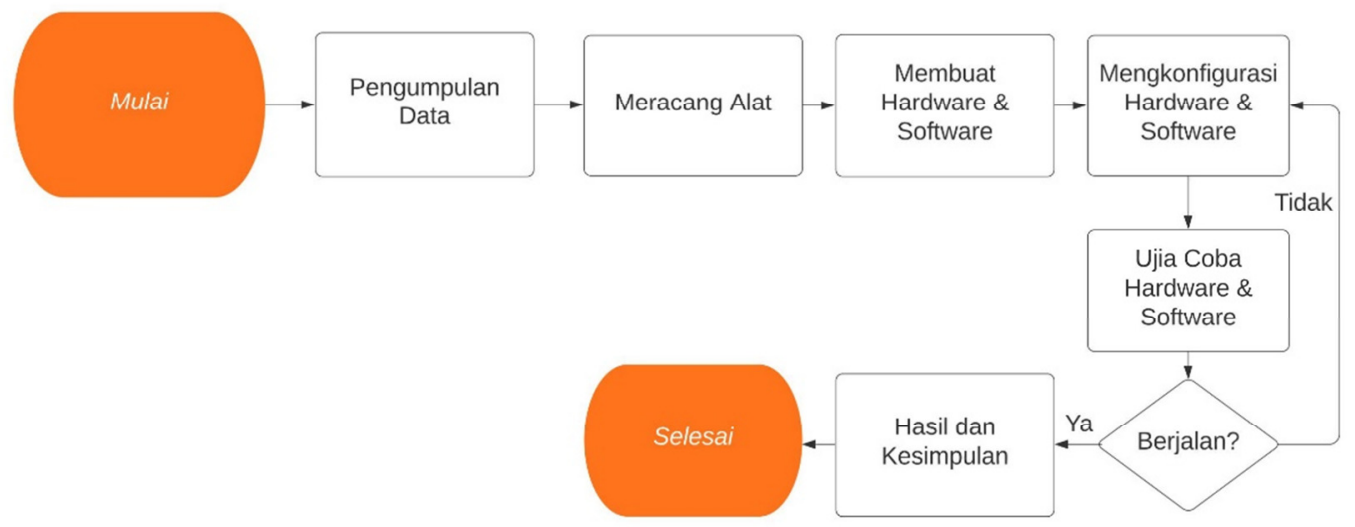

Gambar 2 Flowchart Perancangan

\section{HASIL DAN PEMBAHASAN}

\subsection{Analisis Gambaran Objek Penelitian}

Serbuk atau debu adalah suatu zat keras yang sangat berukuran sangat kecil terbawa oleh keadaan. Zat ini terbentuk dikarenakan suatu proses fraktur seperti penggilingan, penghancuran terhadap benda padat. Debu adalah molekul padat kecil yang ada di udara (airbone) yang tidak mengalami modifikasi kimia atau fisik dari zat padat awal, menurut Mine Safety and Health Administration (MSHA). Melihat debu menempel di barang yang sudah lama tidak tersentuh. Tidak hanya barang, debu juga dapat kamu temukan di beberapa sudut ruangan. Semua orang akan dengan gesit untuk menutup hidung saat terkena paparan debu. Indera penciuman manusia memiliki perlindungan tersendiri untuk mencegah adanya debu yang masuk ke pernapasan. Tetapi, tidak semua debu bisa tersaring oleh bulu hidung. Semakin kecil bentuk debu, semakin besar kemungkinan debu masuk ke paru-paru. Hal itu tentunya akan membahayakan kesehatan. 
Tergantung pada kondisi cuaca, kualitas polusi udara (debu) dapat dipengaruhi oleh suhu udara. Karena suhu tinggi, udara lebih renggang, menghasilkan tingkat polusi yang lebih rendah. Sebaliknya, suhu dingin menyebabkan udara menjadi lebih padat, sehingga suhu di udara menjadi lebih besar. Pusat pada suatu zat dapat dipengaruhi oleh kelembapan udara. Kualitas debu di udara dipengaruhi oleh kelembaban udara. Ketika kelembaban di udara tinggi, polutan udara dapat bereaksi dengan kelembaban di udara untuk membentuk bahan kimia lain yang kurang berbahaya yang disebut polutan sekunder.[8] Salah satu masalah terbesar yang mungkin harus ditangani saat membiarkan ruangan kosong terlalu lama adalah kelembapan yang bisa muncul di berbagai bagian rumah. Baik karena cuaca jelek maupun kerusakan, noda dan bau tak sedap bisa terjadi. Apabila anda akan meninggalkan ruangan dengan waktu lama, mungkin harus memeriksa keadaannya dari waktu ke waktu, tetapi tidak harus setiap minggu.Namun biasanya dengan memantau secara manual memakan waktu dan tenaga dimana sebagian pekerja sedang WFH(Work From Home), yang dimana biasanya pekerja harus terus memantau ruangan yang belum tentu kotor atau bersihnya Alat yang digunakan terdiri dari Arduino UNO D1 R1, Sensor Suhu DHT11, Sensor Debu GP2Y1010AU0F , Kabel Jumper Male Female \& Male Male, Bread Board.

\subsection{Analisis Batasan Sistem}

Berikut batasan sistem yang akan dibangun untuk mengukur ketebalan debu dan suhu udara menggunakan keluaran Telegram pada penelitian ini:

1. Alat ini diciptakan untuk berfungsi sebagai platform untuk memfasilitasi tugas-tugas yang sebelumnya tampak tidak efektif.

2. Sistem yang digunakan dengan memasangkan sensor debu dan suhu pada ruangan yang tidak digunakan yang berfungsi sebagai alat untuk mengetahui ketebalan debu, dan tingkatan suhu yang tersedia pada ruangan

3. Jika alat telah diterapkan sesuai dengan deskripsi alat yang diproduksi, dapat dijalankan dan bekerja sebagaimana mestinya.

4. Penggunaan sistem informasi melalui media internet sebagai sumber informasi perantara antara alat dan penggunanya.

5. Pengguna bisa mengetahui berapa ketebalan debu dan tingkatan suhu pada rungan dengan media aplikasi chat Telegram yang telah ada untuk menampilkan data dari alat yang telah di buat secara realtime. Dan aplikasi Telegram juga dapat diakses menggunakan smartphone maupun komputer dengan menginstall aplikasi diapp atau dengan membuka web Telegram. Jadi pengguna dapat dimudahkan untuk melihat updatean data tersebut.

6. Arduino UNO sebagai pusat untuk mengendalikan, dan aplikasi Telegram digunakan sebagai media output antara sensor dan Arduino UNO

7. Bahasa pemrograman Arduino $\mathrm{C}$ digunakan untuk membuat proyek ini

8. Telegram ialah sebuah aplikasi pengirim pesan multiplatform yang berbasis awan yang gratis. Telegram bisa dibuka melalui smartphone dan perangkat komputer.

9. Wemos D1 R1 berguna sebagai pusat kontrol dan juga berguna sebagai pengendali dari sensor.

\subsection{Analisis Masukan}

Analisis masukan dari rancangan alat pemantau ketebalan debu dan suhu sensor memiliki tingkat kesulitan dalam mengkalibrasi data hasil yang tidak selalu menunjukkan hasil kalibrasi yang akurat sesuai dengan perintah pada program dimana sensor telah terpasang dan terhubung dengan mikrokontroler Arduino UNO D1 R1 dimana sensor telah diprogram pada Mikrokontroler Arduino UNO D1 R1. 


\subsection{Analisis Keluaran}

Langkah ini digunakan untuk mengidentifikasi keluaran dari alat yang telah dikembangkan, yaitu: dengan aplikasi chat Telegram sebagai media pemantaunya. Dimana jika ingin mengecek status ketebalan debu dan memantau suhu tinggal membuka botchat yang sudah dibuat di aplikasi Telegram.

\subsection{Analisa Kebutuhan Komponen}

1. Perangkat Keras

Demi menciptakan alat pemantau debu dan suhu ini diperlukan perangkat keras atau Hardware sebagai berikut:

Tabel 1. Kebutuhan Hardware

\begin{tabular}{|c|c|c|c|}
\hline No & Nama Alat & Jumlah & $\begin{array}{c}\text { Gambar } \\
\text { Alat }\end{array}$ \\
\hline 1 & WEMOS D1 R1 & 1 buah \\
\hline 2 & DHT 11 & 1 buah & \\
\hline 3 & $\begin{array}{l}\text { Sensor Debu } \\
\text { GP2Y1010AU0F }\end{array}$ & 1 buah & \\
\hline 4 & $\begin{array}{l}\text { Kabel Jamper } \\
\text { Male Female \& } \\
\text { Male Male }\end{array}$ & 2 Set & \\
\hline
\end{tabular}

Tabel 2. Kebutuhan Hardware Tambahan

\begin{tabular}{|c|l|c|c|}
\hline No & \multicolumn{1}{|c|}{ Nama Alat } & Jumlah & Gambar Alat \\
\hline 5 & $\begin{array}{l}\text { Kabel } \\
\text { Konektor } \\
\text { USB }\end{array}$ & 1 buah \\
\hline 6 & Bread Board & 1 buah \\
\hline
\end{tabular}


2. Perangkat Lunak

Aplikasi Arduino IDE (Integrated Development Environment) diperlukan untuk membuat program di papan Arduino. Dan disini juga menggunakan aplikasi tambahan Telegram sebagai media pemantauan ketebalan debu dan suhunya.

Prinsip Kerja

Prinsip kerja dari system Sistem Pemantau Ketebalan Debu dan Suhu menggunakan aplikasi Telegram, adalah sebagai berikut ini:

\section{DHT11}

DHT-11 adalah perangkat yang dapat bekerja sebagai sensor suhu dan kelembaban pada saat yang sama, dan juga mendeteksi dua parameter (suhu dan kelembaban) dalam satu lingkungan pada saat yang sama dan menghasilkan sinyal digital. Jenis termistor NTC (Koefisien Suhu Negatif) di DHT-11 sangat membantu sebagai pengukur suhu. Sebuah sensor untuk mendeteksi kelembaban tipe resistif juga disertakan dalam DHT-11, serta mikrokontroler 8-bit yang memproses kedua sensor dan mengirimkan data ke pin output secara dua arah kabel tunggal.[9] Sensor DHT11 biasanya memiliki kalibrasi yang bisa dibilang pembacaan suhu dan kelembabannya cukup akurat. Data kalibrasi disimpan dalam memori program OTP, juga dikenal sebagai nama koefesien kalibrasi. Sensor ini memiliki 4 pin, ada juga sensor DHT11 dengan PCB breakout hanya 3 pin.[10]

2. Sensor Debu GP2Y1010AU0F

GP2Y1010AU0F Dasar pengoperasian sensor ini adalah untuk mendeteksi debu atau partikel lain, setelah itu cahaya dipantulkan kembali ke penerima. Cahaya dipantulkan pada partikel saat melewati seluruh permukaan, dan kemudian diubah menjadi tegangan oleh fotodioda. Sensor Debu Optik GP2Y1010AU0F Ini adalah sensor debu yang menggunakan teknologi inframerah. Sensor ini bekerja berdasarkan gagasan cahaya yang dipantulkan oleh partikel di permukaan dan kemudian diubah menjadi listrik oleh fotodioda. Agar perubahan dapat dibaca, tegangan harus diperkuat. Keluaran sensor adalah tegangan analog yang sebanding dengan densitas debu yang diamati, dengan sensitivitas $0,5 \mathrm{~V} / 0,1 \mathrm{mg} / \mathrm{m} 3$ dan sensitivitas $0,5 \mathrm{~V} / 0,1 \mathrm{mg} / \mathrm{m} 3$. Contoh itu, tegangan akan meningkat menjadi $0,5 \mathrm{~V}$ untuk setiap peningkatan kepadatan debu $0,1 \mathrm{mg} / \mathrm{m} 3$. [6]

3. Wemos D1 R1

Wemos D1 R1 merupakan board yang menyerupai Arduino Uno dan memanfaatkan ESP8266 sebagai modul WiFi. Wemos D1 R1 memiliki keunggulan sebagai berikut: bersifat open source, kompatibel dengan Arduino, dapat diprogram menggunakan Arduino IDE, pinout kompatibel dengan Arduino Uno, dapat berdiri sendiri tanpa memerlukan mikrokontroler lain, dan dilengkapi CPU 32-bit dengan kecepatan clock $80 \mathrm{MHz}$, Python dan Lua[4] dapat digunakan untuk memprogram dalam bahasa tingkat tinggi ini.

Perancangan sistem alat pemantau ketebalan debu dan suhu berbasis Arduino UNO D1 R1 dan terhubung dengan Telegram. 


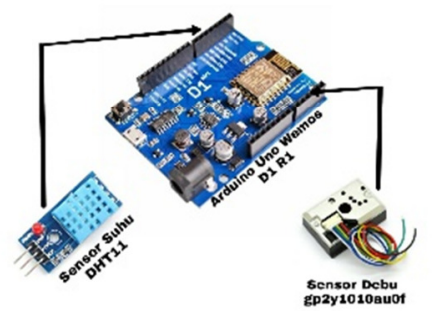

Gambar 3. Rangkaian Sistem Pengukur Ketebalan Debu Dan Suhu

Keterangan:

1. Pada Sensor Debu DHT11, hubungkan semua pinnya ke Arduino Uno, pin VCC hubungkan ke pin VIN, pin Data hubungkan ke pin D1, dan pin GND hubungkan ke pin GND.

2. Kemudian dihubungkan Sensor Debu GP2Y1010AU0F ke Arduino UNO, tapi sebelum itu hubungkan semua pinnya dari pin1 hingga pin6 ke BREAD BOARD, dikarenakan semua kabel yang ada di Sensor Debu GP2Y1010AU0F sangat rentan lepas, jadi di perlukan BREAD BOARD agra tidak mudah terlepas, lalu menyambungkan kabel BREAD BOARD sebelumnya ke Arduino UNO dengan menggunakan kabel jumper male to male.

3. Hubungkan pin1 dan pin6 Sensor Debu GP2Y1010AU0F ke Resistor, Kapasitor (positif) di BREAD BOARD, setelah itu sambungkan ke pin $5 \mathrm{~V}$ pada Arduino UNO. pin2 dan pin4 sambungkan ke Kapasitor (negatif) di Bread Board, lalu hubungkan ke pin GND di Arduino UNO. Hubungkan pin3 ke BREAD BOARD, dan terakhir hubungkan ke pin D2 di Arduino UNO.

\section{Cara Kerja Teknologi}

Dengan mengikuti skema dan juga rangkaian yang telah dibangun, alat ini akan bekerja dengan sempurna. Ada sensor debu sebagai pendeteksi ketebalan debu, dan sensor suhu DHT11 sebagai pendeteksi suhu dan semua sensor ini akan beroperasi secara konstan, tanpa menargetkan data yang diterima oleh sensor.

Semua tugas ini akan beroperasi dengan sempurna jika dibangun serta diberi daya sesuai dengan skema dan alat yang telah dikonfigurasi menggunakan perangkat lunak Arduino UNO IDE. Setelah program Arduino berhasil diunggah dan perakitan telah diaktifkan, semua komponen atau perangkat akan menjalankan fungsinya menggunakan perangkat lunak Arduino UNO dan software/aplikasi Telegram 


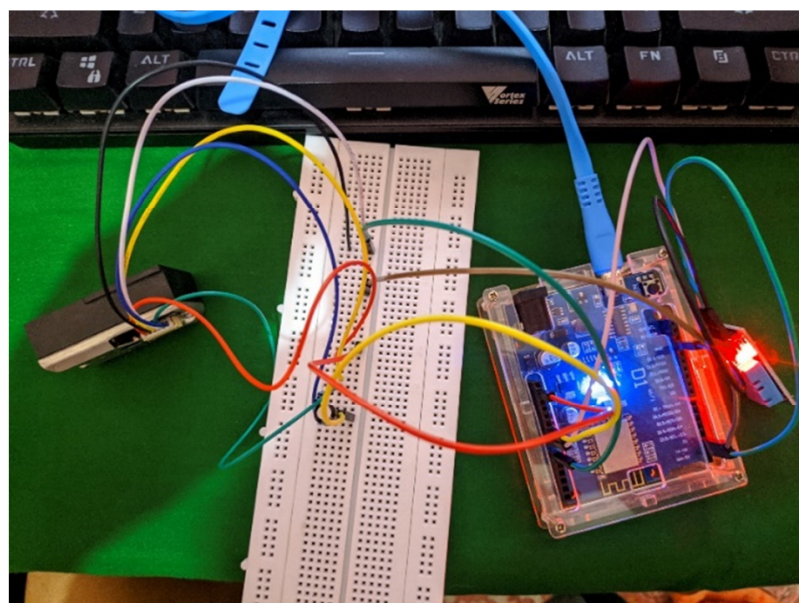

Gambar 4. Rangkaian Komponen dan Akan Dicoba

1. Ketika Arduino Uno terhubung ke USB Laptop, LED Biru pada Arduino Uno menyala dan menyalakan komponen lain yang terpasang pada Wemos D1 R1.

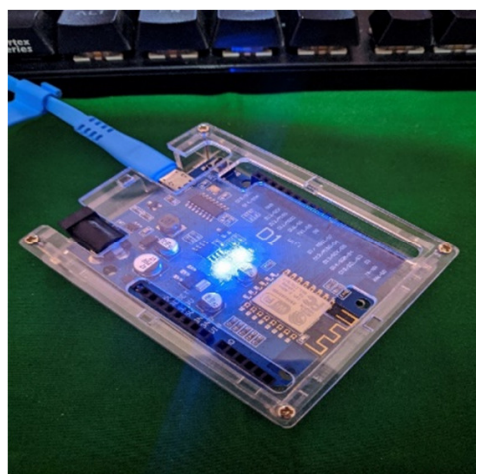

Gambar 5. Arduino UNO yang Sudah Terhubung pada USB Laptop

2. Masukan kodingan ke Arduino IDE setelah terhubung ke USB Laptop

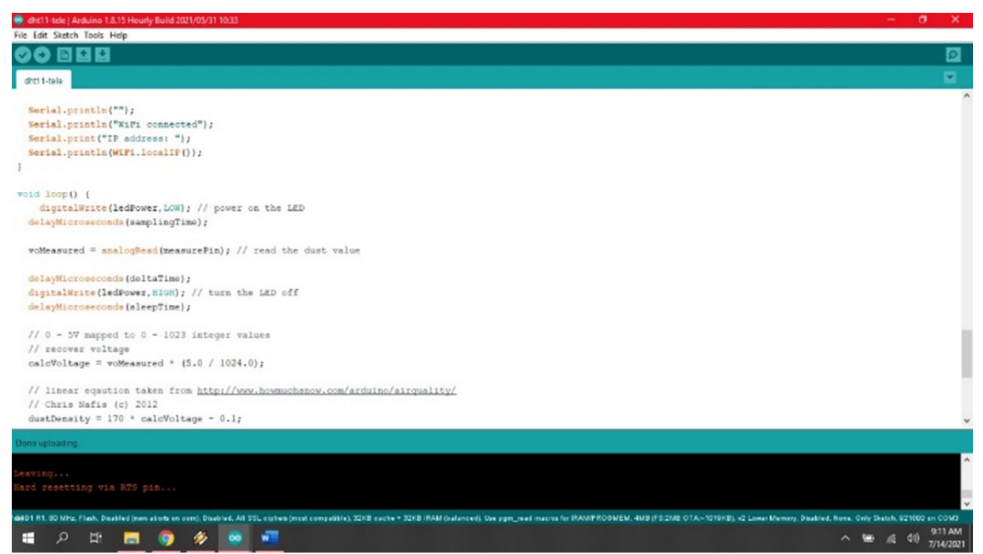

Gambar 6. Pembuatan Program Menggunakan Arduino IDE 
3. Setelah kodingan telah done compiling, rakit semua komponen lalu upload kodingan tersebut

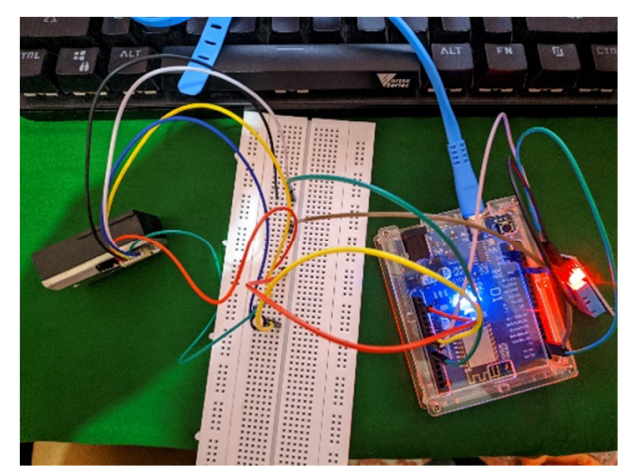

Gambar 7. Alat Telah di Rakit dan Program Telah di Upload

4. Setelah semua selesai Wemos D1 R1 sudah terhubung dengan koneksi internet, selanjutnya adalah masuk ke telegram aplikasi/web telegram, lalu login atau registrasi untuk masuk ke telegramnya, setelah itu ke bagian pencarian lalu ketik "Bot Father" lalu pilih
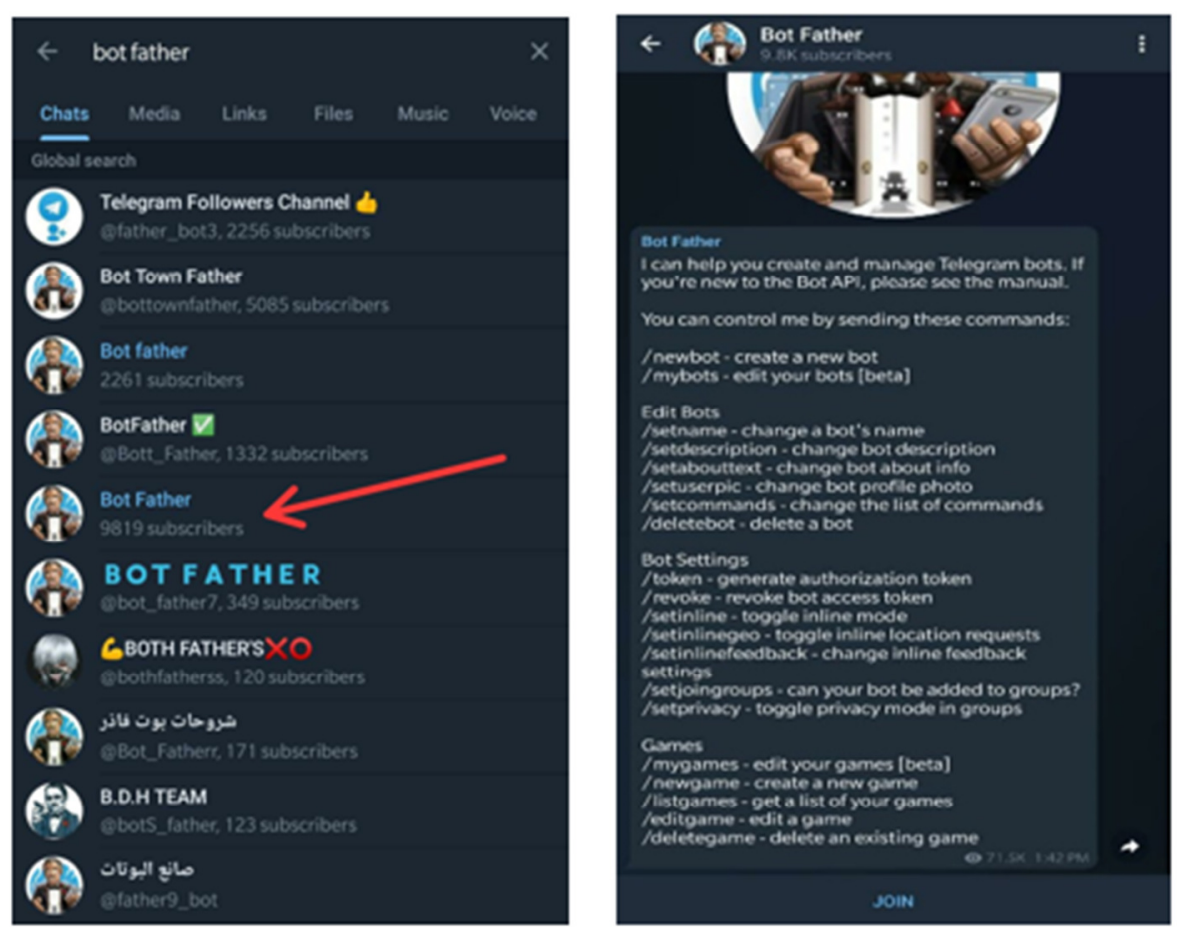

Gambar 8 Pencarian Botchat dan Tampilan awal

5. Kemudian setelah menemukan tempat untuk membuat botchat disini menggunakan BOT FATHER, lalu buat botchat sesuai intruksinya. 

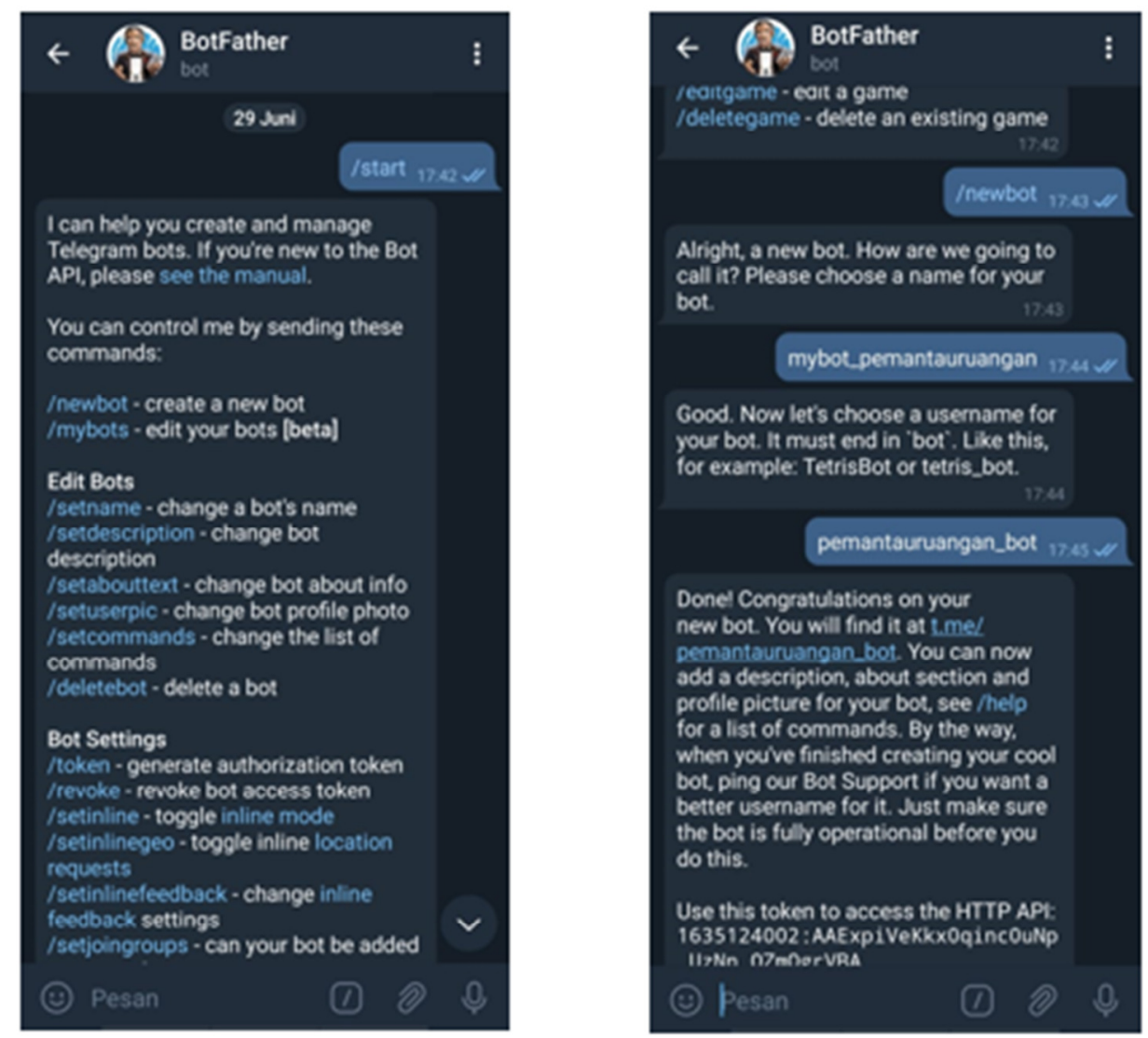

Gambar 9 Proses Pembuatan Botchat

6. Apabila telah selesai dalam proses pembuatan botchat, lalu Kembali lagi ke bagian pencarian lalu cari nama botchat yang telah kita buat tadi.

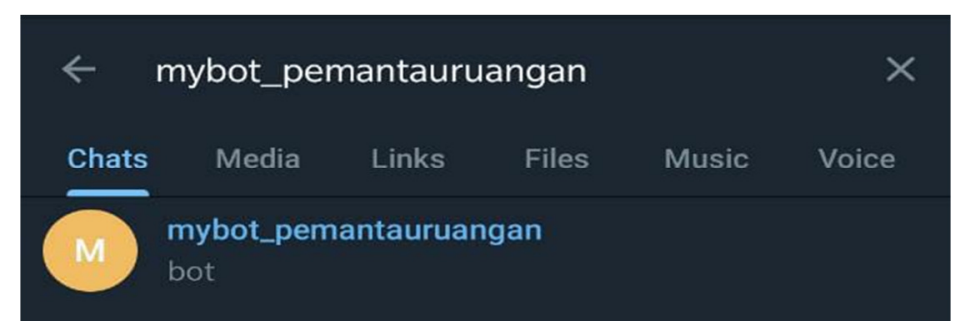

Gambar 10 Proses Pencarian Botchat yang Sudah Dibuat Tadi

7. Setelah sudah menemukan botchat yang di buat tadi, lalu kita masuk ke botchat tadi, lalu Ketika kita memilih 'START' botchat akan merespon dengan otomatis, dikarenakan program kita sudah di upload, nanti akan muncul opsi yang kita buat tadi botchat. 

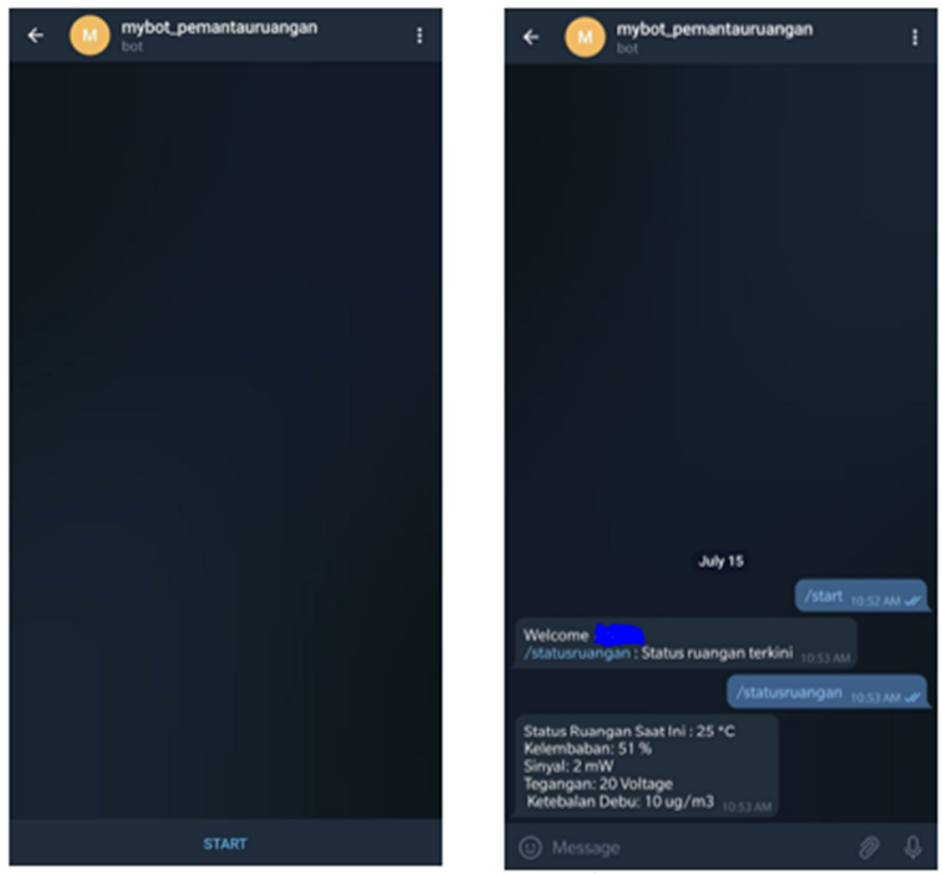

Gambar 11 Tampilan yang Akan Keluar Sesuai Program

Pengujian di lakukan dengan melihat hasil datanya melalui sensor Debu GP2Y1010AU0F dan sensor Suhu DHT11 yang di pasangkan pada lantai atau meja yang datanya akan di kirimkan ke Aplikasi atau Software Telegram.

Tabel 3. Simulasi Pengujian Alat

\begin{tabular}{|c|c|c|c|}
\hline No. & $\begin{array}{c}\text { DHT11 } \\
\text { (Suhu dan Kelembaban) }\end{array}$ & $\begin{array}{c}\text { GP2Y1010AU0F } \\
\text { (Optical Dust Sensor) }\end{array}$ & Tampilan Telegram \\
\hline 1 & $\begin{array}{l}25^{*} \mathrm{C} \\
51 \%\end{array}$ & $\begin{array}{l}2 \mathrm{~mW} \\
20 \mathrm{Voltage} \\
10 \mathrm{ug} / \mathrm{m} 3\end{array}$ & $\begin{array}{l}\text { Suhu: } 25^{*} \mathrm{C} \\
\text { Kelembaban: } 51 \% \\
\text { Sinyal: } 2 \mathrm{~mW} \\
\text { Tegangan: } 20 \text { Voltage } \\
\text { Ketebalan Debu: } 10 \mathrm{ug} / \mathrm{m} 3\end{array}$ \\
\hline 2 & $\begin{array}{l}26 * \mathrm{C} \\
53 \%\end{array}$ & $\begin{array}{l}31 \mathrm{~mW} \\
38 \text { Voltage } \\
44 \mathrm{ug} / \mathrm{m} 3\end{array}$ & $\begin{array}{l}\text { Suhu: } 26^{*} \mathrm{C} \\
\text { Kelembaban: } 53 \% \\
\text { Sinyal: } 31 \mathrm{~mW} \\
\text { Tegangan: } 38 \text { Voltage } \\
\text { Ketebalan Debu: } 44 \mathrm{ug} / \mathrm{m} 3\end{array}$ \\
\hline 3 & $\begin{array}{l}26 * \mathrm{C} \\
53 \%\end{array}$ & $\begin{array}{l}70 \mathrm{~mW} \\
55 \mathrm{Voltage} \\
64 \mathrm{ug} / \mathrm{m} 3\end{array}$ & $\begin{array}{l}\text { Suhu: } 26^{*} \mathrm{C} \\
\text { Kelembaban: } 53 \% \\
\text { Sinyal: } 70 \mathrm{~mW} \\
\text { Tegangan: } 55 \text { Voltage } \\
\text { Ketebalan Debu: } 64 \mathrm{ug} / \mathrm{m} 3\end{array}$ \\
\hline
\end{tabular}

Maulana, et., al [Sistem Pemantauan Ketebalan Debu \& Suhu Pada Ruangan Menggunakan Aplikasi Telegram Berbasis IoT] 
Dapat diamati dari table diatas dapat diketahui dengan ditemukan perbedaan dalam data yang di terima oleh sensor Debu dan Suhu dan di tampilkan ke Telegram sebagai berikut:

1. Pada kondisi ke-1 sensor suhu mendeteksi bahwa Suhu dan Kelembaban saat ini adalah $25 * \mathrm{C}$ dan $51 \%$, dan di saat bersamaan pula sensor Debu mendeteksi data yang di terima adalah, $2 \mathrm{~mW}, 20$ Voltage, dan $10 \mathrm{ug} / \mathrm{m} 3$, jadi dari ke2 sensor tersebut Telegram akan menerima data yang lebih jelas adalah:

Suhu: $25^{*} \mathrm{C}$

Kelembaban: $51 \%$

Sinyal: $2 \mathrm{~mW}$

Tegangan: 20 Volatge

Ketebalan Debu: $10 \mathrm{ug} / \mathrm{m} 3$

2. Pada kondisi ke-2 sensor suhu mendeteksi bahwa Suhu dan Kelembaban saat ini adalah $26 * \mathrm{C}$ dan $53 \%$, dan di saat bersamaan pula sensor Debu mendeteksi data yang di terima adalah, $31 \mathrm{~mW}, 38$ Voltage, dan $44 \mathrm{ug} / \mathrm{m} 3$, jadi dari ke2 sensor tersebut Telegram akan menerima data yang lebih jelas adalah:

Suhu: $26^{*} \mathrm{C}$

Kelembaban: $53 \%$

Sinyal: $31 \mathrm{~mW}$

Tegangan: 38 Volatge

Ketebalan Debu: $44 \mathrm{ug} / \mathrm{m} 3$

3. Pada kondisi ke-3 sensor suhu mendeteksi bahwa Suhu dan Kelembaban saat ini adalah $26^{*} \mathrm{C}$ dan $53 \%$, dan di saat bersamaan pula sensor Debu mendeteksi data yang di terima adalah, $70 \mathrm{~mW}, 55$ Voltage, dan $64 \mathrm{ug} / \mathrm{m} 3$, jadi dari ke2 sensor tersebut Telegram akan menerima data yang lebih jelas adalah:

Suhu: $26 * \mathrm{C}$

Kelembaban: $53 \%$

Sinyal: $70 \mathrm{~mW}$

Tegangan: 55 Volatge

Ketebalan Debu: 64 ug/m3

\section{KESIMPULAN}

Dari yang telah diteliti dan sudah melakukan pengujian tentang Sistem Pemantau Ketebalan Debu dan Suhu menggunakan aplikasi Telegram mendapat kesimpulan. Mulai dari sistem alat ini berjalan menggunakan DHT11 dan GP2Y1010AU0F yang dimana sensor ini berfungsi sebagai inputan yang kemudian dilanjutkan oleh WEMOS D1 R1 dan akan dikeluarkan di BotChat Telegram. Melalui sensor GP2Y1010AU0F, alat ini merupakan element penting yang dimana debu masuk kedalam lubang sensor debu setelah diproses maka mengeluarkan outputan tegangan yang akan dimunculkan oleh BotChat Telegram. Dengan adanya alat ini pekerjaan bisa terbantu karena sedikit memudahkan dalam hal memantau dari jarak jauh yang biasanya melihat melalui LCD atau melihatnya secara langsung sekarang hanya melihat lewat Telegram. Sangat penting sekali memantau ruangan yang kosong agar tetap terjaga kebersihan dan kesehatan ruangan. Hasil yang diperoleh dari prototipe ini perlu pengujian lebih lanjut lagi didalam proses bekerjanya alat ini. 


\section{SARAN}

Dengan kemajuan teknologi dimasa yang akan datang diharapkan dengan adanya alat ini bisa bias lebih berkembang lagi memudahkan dalam hal memantau ruangan dari jarak jauh, meskipun alat ini belum maksimal lagi dalam segi fiturnya. Kedepannya alat ini masih memungkinkan untuk bisa dikembangkan dengan menambah beberapa fitur lagi agar lebih simple dan lebih berguna untuk mengontrol dari jarak jauh.

\section{UCAPAN TERIMA KASIH}

Disini penulis mengucapkan sangat berterima kasih kepada pihak yang telah dilibatkan dan sangat mengapresiasi terhadap semua pihak yang telah membantu melancarkan serta memudahkan dalam proses pembuatan jurnal ini hingga akhir. Mulai dari memberikan financial untuk pembuatan alat maupun mendukung secara materi.

\section{DAFTAR PUSTAKA}

[1] M. Shidiq, 2018. "Pengertian Internet of Things (IoT) - Menara Ilmu Otomasi SV UGM," Sekolah Vokasi UGM Departemen Teknik Elektro dan Informatika.

[2] B. Narpati, I. Lubis, K. I. Meutia, and E. P. Ningrum, 2021. "Produktivitas Kerja Pegawai yang Dipengaruhi oleh Work From Home (WFH) dan Lingkungan Kerja Selama Masa Pandemi," J. Ilm. Manaj. Forkamma, Vol. 4, No. 1,

[3] E. Permana and S. Herawati, "Rancang Bangun Sistem Monitoring Suhu Ruangan Bagian Pembukuan Berbasis Web Meggunakan Mikrokontroler Arduino Uno R3," J. Teknol. Inf. dan Komun. STMIK Subang, no. April, 2018.

[4] S. Syahrorini and A. Ahfas, 2018, "Aplikasi Alat Ukur Debu Berbasis Sms dan Analisis Model Dispersi Gauss,” Elinvo (Electronics, Informatics, Vocat. Educ., Vol. 3, No. 1, doi: 10.21831/elinvo.v3i1.19241.

[5] R. Juniyantara Putra, N. Putra Sastra, and D. M. Wiharta, 2018, "Pengembangan Komunikasi Multikanal Untuk Monitoring Infrastruktur Jaringan Berbasis Bot Telegram,” J. SPEKTRUM, Vol. 5, No. 2, doi: 10.24843/spektrum.2018.v05.i02.p19.

[6] A. D. Mulyanto, 2020, "Pemanfaatan Bot Telegram Untuk Media Informasi Penelitian," MATICS, Vol. 12, No. 1, doi: 10.18860/mat.v12i1.8847.

[7] R. S. Kusumadiarti and H. Qodawi, 2021, "Implementasi Sensor Water Level Dalam Sistem Pengatur Debit Air di Pesawahan,” J. PETIK, Vol. 7, No. 1, doi: 10.31980/jpetik.v7i1.957.

[8] M. Subarkah, B. Triyantoro, and K. Khomsatun, 2018, "Hubungan Paparan Debu dan Masa Kerja Dengan Keluhan Pernafasan pada Tenaga Kerja Cv. Jiyo'g Konveksi Desa Notog Kecamatan Patikraja Kabupaten Banyumas Tahun 2017,” Bul. Keslingmas, Vol. 37, No. 3, doi: 10.31983/keslingmas.v37i3.3874. 
[9] A. Sumarjono, 2018 "Sistem Monitoring dan Pengendalian Suhu Ruangan di Laboratorium Dengan Menggunakan Labview Berbasis Arduino Agus Sumarjono," Integr. Lab J., Vol. 06, No. 1405,

[10] bayu gusti Putra and H. Effendi, "Rancangan Bangun Instrumen Deteksi Dini Kondisi Kondenser AC Central (Chiller) Berbasis Mikrokontroler Dengan Media Komunikasi Sms Gateway,” Sunusoida, Vol. XX, 2018. 